\title{
Consumo de Fibra em Detergente Neutro por Bovinos em Confinamento
}

\section{Edenio Detmann ${ }^{1}$, Augusto César de Queiroz 2,3, Paulo Roberto Cecon ${ }^{4,3}$, Joanis Tilemahos Zervoudakis ${ }^{5,3}$, Mário Fonseca Paulino ${ }^{6,3}$, Sebastião de Campos Valadares Filho7,3, Luciano da Silva Cabral ${ }^{8}$, Rogério de Paula Lana9,3}

\begin{abstract}
RESUMO - Objetivou-se avaliar o consumo de fibra em detergente neutro (FDN) por bovinos em confinamento e os principais fatores que influenciam esta variável, correlacionado-a ao consumo de matéria seca (MS) total. Foram avaliados dados publicados na Revista da Sociedade Brasileira de Zootecnia e Revista Brasileira de Zootecnia, no período de 1991 e 2000, totalizando 45 trabalhos científicos e 181 médias de tratamentos. O nível de nutrientes digestíveis totais mostrou-se negativamente correlacionado ao nível de FDN nas dietas $(\mathrm{r}=-0,6006 ; \mathrm{P}<0,01)$. A concentração de carboidratos não-fibrosos influenciou de forma negativa a digestibilidade da FDN (DFDN) ( $r=-0,1631 ; \mathrm{P}<0,09)$; contudo, nenhum procedimento estatístico empregado permitiu detectar efeitos da DFDN sobre o consumo de MS total $(\mathrm{P}>0,10)$. A descrição da relação entre consumo de MS e nível de FDN na dieta foi realizada de forma bifásica, buscando similaridade às curvas propostas por um modelo estático de predição do consumo. A interseção das curvas projetou consumo de FDN (CFDN) de 11,93 g/kg PV. No entanto, a avaliação dos CFDN estimados durante a fase atribuída aos controladores físicos do consumo mostrou inconstância, gerando divergência entre os pontos de consumo máximo de MS e FDN, indicando ser a transição entre os mecanismos físicos e fisiológicos, possivelmente, determinada por um intervalo com interação entre mecanismos. A avaliação do CFDN em função do nível de volumosos nas dietas mostrou perfis estáveis em concentrações superiores a 60\%, sendo de 13,53 g/kg PV no intervalo de 80 a 100\%. Possíveis interações com a fração indigestível da FDN podem ditar a plasticidade do limite diário de CFDN.
\end{abstract}

Palavras-chave: bovinos, consumo, fibra em detergente neutro, fibra em detergente neutro indigestível

\section{Neutral Detergent Fiber Intake by Feedlot Cattle}

\begin{abstract}
The objective of this work was to evaluate the intake of neutral detergent fiber (NDF) by fedlot cattle, the principal factors that influencing this variable, and to correlate the NDF to total dry matter (DM) intake. The data published at the Brazilian Journal of Animal Science Society and Brazilian Journal of Animal Science among the years of 1991 and 2000, totaling 45 scientific works and 181 averages of treatments, were evaluated. The level of total digestible nutrients was negatively correlated to the level of NDF in diets $(\mathrm{r}=-0.6006 ; \mathrm{P}<.01)$. The concentration of non-fibrous carbohydrates influenced in a negative way the digestibility of NDF (NDFD) ( $r=-0.1631 ; \mathrm{P}<.09)$; however, no statistical procedure employed allowed to detect effects of NDFD on the total DM intake (P>.10). The description of the relationship among total DM intake and level of NDF in the diet was accomplished using a biphasic profile, looking for similarity to the curves proposed by the static model of DM intake prediction. The intersection of the curves projected a intake of NDF (NDFI) of $11.93 \mathrm{~g} / \mathrm{kg} \mathrm{LW}$. However, the evaluation of NDFI estimated during the phase attributed to the physical controllers of intake showed inconstancy, generating divergence among the points of maximum intake of DM and NDF. This profile indicated that the transition among the physical and physiologic mechanisms is, possibly, delimited by an interval with interaction among mechanisms. The evaluation of NDFI according to the level of forage in the diets showed stable profiles in concentrations above to $60 \%$, being of 13.53 $\mathrm{g} / \mathrm{kg} \mathrm{LW}$ in the interval from 80 to $100 \%$. Possible interactions with the indigestible fraction of NDF can dictate the plasticity of the daily limit of NDFI.
\end{abstract}

Key Words: cattle, indigestible neutral detergent fiber, intake, neutral detergent fiber

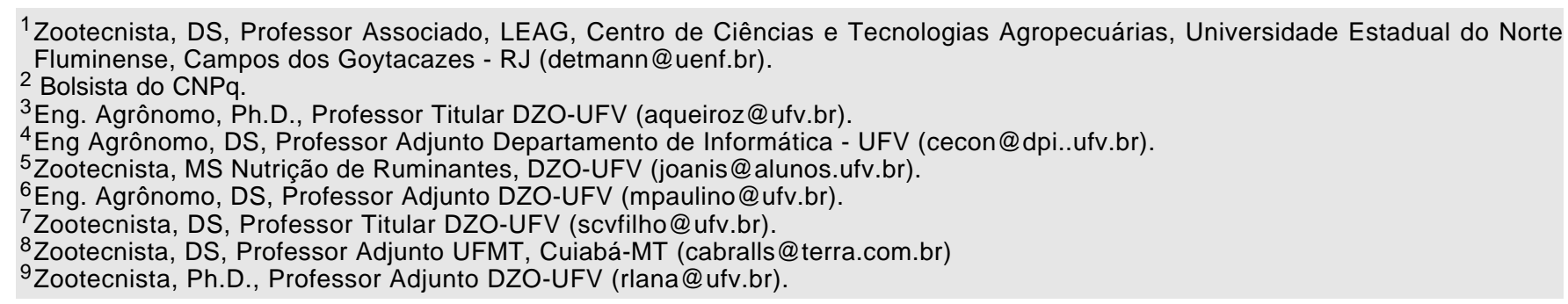




\section{Introdução}

Os determinantes primários da conversão de forragens a produtos animais são: o consumo de matéria seca ou de energia; a digestibilidade e as eficiências de conversão da energia digestível a energia metabolizável e desta a energia líquida (Waldo, 1986). Como o componente primário desta cadeia, o consumo de matéria seca assume importante papel nos estudos de nutrição, pois estabelece a quantidade de nutrientes disponíveis para a produção e manutenção do bem estar animal (NRC, 2001).

A maior limitação dos modelos nutricionais para formulação de rações se concentra na inacurácia da predição do consumo de matéria seca, o qual engloba mais intimamente as variações na produção do que a digestibilidade dos alimentos (Rayburn \& Fox, 1993), gerando uma busca contínua de procedimentos para obtenção de estimativas confiáveis desta variável.

O consumo de matéria seca é, em essência, reflexo direto do potencial genético do animal (Allen, 2000), no qual ações coordenadas para o modelo determinado de crescimento esquelético, muscular e dos demais tecidos metabolicamente ativos, englobando direcionamentos homeostásicos e homeorréticos, contribuem para o alcance ou manutenção de um status energético de forma contínua (regulação a longo prazo) (Mertens, 1996). No entanto, refeições são realizadas diariamente, sendo o comportamento ingestivo em curtos intervalos (horas, dias), envolvido por estímulos externos e da parte inicial do trato digestivo (Mertens, 1996). Cada alimento ou ração ingerida incita, por diferentes mecanismos, os sistemas de fome/saciedade resultando em uma série de refeições de tamanhos distintos, dentro de um ritmo circadiano biológico, com alternâncias entre períodos de ruminação e descanso. Portanto, para cada alimento/ração existe um modelo de alimentação específico e, consequentemente, um nível de ingestão de matéria seca (regulação a curto prazo) (Dulphy \& Demarquilly, 1994).

No desenvolvimento de equações ou modelos de predição do consumo por ruminantes, aplicáveis a uma grande variedade de requerimentos animais e características dietéticas, faz-se importante a aplicação de conceitos teóricos fisiológicos e nutricionais. Assim, se o consumo diário é a meta primária, teorias relacionadas à regulação do consumo a longo prazo são as mais apropriadas como ponto inicial para derivação das equações. No entanto, equações está- ticas podem ser mais realísticas ao início do desenvolvimento do modelo, pois estimar-se-á o consumo necessário relacionado à ingestão diária quando os animais estão adaptados à dieta, em um estado de equilíbrio (Mertens, 1987).

Dentro desse contexto, empregando características de alimento e exigências nutricionais, Mertens (1987), com base principalmente nos resultados demonstrados por Conrad et al. (1964), propôs um modelo estático de natureza bifásica para estimação do consumo voluntário em vacas em lactação. Segundo este modelo, dietas que apresentam níveis elevados de energia têm seu consumo determinado pelo atendimento das exigências do animal. Por outro lado, dietas com baixos níveis energéticos têm como principal entrave ao consumo a capacidade física de ingestão ou de enchimento ruminal.

No desenvolvimento deste sistema integrativo estático para predição do consumo, Mertens (1994) sugeriu a concentração de fibra em detergente neutro (FDN) na dieta como unidade básica de aplicação, visto ser inversamente relacionada ao conteúdo energético e melhor representar a propriedade dos alimentos em ocupar espaço (Mertens, 1987, 1994). Sob estes pressupostos, Mertens (1987) sugeriu que, nos casos em que o consumo seja limitado por entraves físicos, o consumo de FDN mantenha-se próximo ao valor de 12,0 $\pm 1,0 \mathrm{~g} / \mathrm{kg}$ de peso vivo (PV). Embora tenha sido proposto inicialmente para vacas em lactação, vários autores relacionaram este valor em estudos com bovinos em crescimento (Ramos et al., 1996; Ladeira et al., 1999; Dias et al., 2000; Tibo et al., 2000; Véras et al., 2000). Contudo, ressalta-se o fato de esta estimativa ter sido obtida em estudos realizados com forrageiras cultivadas em regiões temperadas, podendo não representar especificamente o comportamento ingestivo de ruminantes alimentados com forrageiras tropicais.

Objetivou-se neste estudo avaliar o consumo de FDN por bovinos em confinamento em regiões tropicais e sua correlação com a ingestão diária de matéria seca (MS).

\section{Material e Métodos}

Foram utilizados dados de experimentos com bovinos confinados, publicados na Revista da Sociedade Brasileira de Zootecnia e na Revista Brasileira de Zootecnia entre os anos de 1991 e 2000, totalizando 45 trabalhos científicos e 181 médias de tratamentos 
(Furtado et al., 1991; Oliveira et al., 1991; Castillo et al., 1993; Gomes et al., 1994; Peixoto et al., 1994a; Peixoto et al., 1994b; Resende et al., 1994; Araújo et al., 1995; Resende et al., 1995; Deresz et al., 1996; Malafaia et al., 1996; Mora et al., 1996; Pereira et al., 1996; Rabello et al., 1996; Ramos et al., 1996; Rodriguez et al., 1996; Vilela et al., 1996; Carvalho et al., 1997; Dutra et al., 1997; Fonseca et al., 1997; Ludovico \& Mattos, 1997; Mayer et al., 1997; Suarez Lodoño et al., 1997; Valadares et al., 1997; Araújo et al., 1998; Queiroz et al., 1998; Ferreira et al., 1999; Ladeira et al., 1999; Miranda et al., 1999; Oliveira et al., 1999; Prado \& Martins, 1999; Rodrigues \& Barbosa, 1999; Signoretti et al., 1999; Bürger et al., 2000; Caldas Neto et al., 2000; Cardoso et al., 2000; Dias et al., 2000; Marques et al., 2000; Martins et al., 2000; Mattos et al., 2000; Pascoal et al., 2000; Prado et al., 2000a; Prado et al., 2000b; Tibo et al., 2000; Véras et al., 2000).

Foram avaliadas as variáveis: consumos de matéria seca (CMS) e de FDN (CFDN); níveis de volumosos (NV), de FDN, de proteína bruta (PB), de carboidratos não-fibrosos (CNF) e de nutrientes digestíveis totais (NDT) na dieta; e digestibilidade total da FDN. A seleção dos trabalhos científicos se deu com base no conteúdo explícito ou implícito dos consumos de matéria seca e de FDN e dos níveis de FDN na dieta, sendo utilizados mesmo nos casos em que alguma das demais variáveis anteriormente listadas não estivesse incluída entre os parâmetros avaliados.

As análises estatísticas envolveram a aplicação de medidas descritivas básicas (média, desvio-padrão e erro-padrão) e análises de correlação, regressão linear (Myers, 1990), regressão não-linear (Souza, 1998), variância e covariância (Steel et al., 1997).

\section{Resultados e Discussão}

As estatísticas descritivas para as variáveis levantadas são mostradas na Tabela 1. Ao efetuar-se o levantamento das informações contidas nas Revistas da Sociedade Brasileira de Zootecnia e Brasileira de Zootecnia, buscou-se a construção de um banco de dados que permitisse boa representatividade das condições alimentares às quais são submetidos os bovinos confinados em condições brasileiras.

De forma geral, as amplitudes totais das diferentes variáveis (Tabela 1) comportaram-se satisfatoriamente frente aos objetivos do estudo, abordando-se dietas que variaram de baixa à alta qualidade. Dessa forma, possibilitaram-se projeções representativas, face ao universo de rações e dietas empregadas na

Tabela 1 - Estatística descritiva para as variáveis analisadas Table 1 - Descriptive statistics for the analyzed variables

\begin{tabular}{|c|c|c|c|c|c|}
\hline $\begin{array}{l}\text { Variável }^{1} \\
\text { Variable }^{1}\end{array}$ & $\begin{array}{l}\text { Média } \\
\text { Mean }\end{array}$ & $\begin{array}{l}\text { Máximo } \\
\text { Maximum }\end{array}$ & $\begin{array}{l}\text { Mínimo } \\
\text { Minimum }\end{array}$ & $\begin{array}{l}\text { Desvio-padrão } \\
\text { Standard deviation }\end{array}$ & $\mathrm{n}$ \\
\hline $\begin{array}{l}\text { CMS (g/kg PV) } \\
D M I(g / k g L W)\end{array}$ & 23,74 & 41,0 & 11,0 & 6,20 & 181 \\
\hline $\begin{array}{l}\text { CFDN (g/kg PV) } \\
N D F I(g / k g L W)\end{array}$ & 11,12 & 22,1 & 3,0 & 3,66 & 181 \\
\hline $\begin{array}{l}\mathrm{NV}(\%) \\
F L(\%)\end{array}$ & 56,78 & 100 & 10 & 18,22 & 164 \\
\hline $\begin{array}{l}\text { FDN (g/kg MS }) \\
N D F(g / k g D M)\end{array}$ & 484,7 & 781,6 & 188,8 & 124,40 & 181 \\
\hline $\begin{array}{l}\text { FDNV (g/kg MS }) \\
N D F F(g / k g D M)\end{array}$ & 388,7 & 781,6 & 44,0 & 148,10 & 131 \\
\hline $\begin{array}{l}\mathrm{PB}(\mathrm{g} / \mathrm{kg} \mathrm{MS}) \\
C P(\mathrm{~g} / \mathrm{kg} D M)\end{array}$ & 128,4 & 200,0 & 61,2 & 26,24 & 166 \\
\hline $\begin{array}{l}\mathrm{CNF}(\mathrm{g} / \mathrm{kg} \mathrm{MS}) \\
N F C(\mathrm{~g} / \mathrm{kg} D M)\end{array}$ & 339,1 & 575,2 & 37,0 & 111,07 & 89 \\
\hline $\begin{array}{l}\operatorname{DFDN}(\%) \\
\operatorname{NDFD}(\%)\end{array}$ & 45,3 & 67,4 & 11,3 & 10,80 & 106 \\
\hline $\begin{array}{l}\text { NDT (\% MS) } \\
T D N(\% D M)\end{array}$ & 64,06 & 82,0 & 45,4 & 7,27 & 95 \\
\hline
\end{tabular}

${ }^{1} \mathrm{CMS}$ = consumo de matéria seca; CFDN = consumo de FDN; NV = nível de volumosos na dieta; FDN = nível de FDN na dieta; FDNV = nível de FDN oriundo de fontes volumosas na dieta; $\mathrm{PB}=$ nível de proteína bruta na dieta; CNF = nível de carboidratos não-fibrosos na dieta; DFDN = digestibilidade total da FDN; NDT = nível de nutrientes digestíveis totais na dieta.

${ }^{1} \mathrm{DMI}=$ dry matter intake; NDFI = NDF intake; $F L=$ forage level in diet; NDF = NDF level in diet; $N D F F=N D F$ from forage level in diet; $C P=C P$ level in diet; $N F C=$ non-fibrous carbohydrate level in diet; NDFD = NDF total digestibility; TDN = total digestible nutrients level in diet . 
estruturação de trabalhos de pesquisa com bovinos em confinamento, no Brasil, e ao comportamento quantitativo do consumo de matéria seca destes animais e sua possível interaçãocom o nível dietético de fibra em detergente neutro.

\section{Avaliação descritiva de variáveis categóricas}

Os consumos de matéria seca e FDN, em função das variáveis categóricas relacionadas à categoria animal (vacas em lactação e bovinos em crescimento e terminação), grupo genético (europeu - E, zebuíno - Z e mestiço $\mathrm{ExZ}$ ) e fonte de alimentos volumosos (silagens, fenos e cana-de-açúcar), são expressos na Tabela 2.

Observaram-se maiores consumos para vacas em lactação quando comparados aos obtidos com animais em crescimento e terminação (Tabela 2). Este quadro suporta o raciocínio lógico de maior consumo para animais em lactação, em função de maiores exigências para mantença e produção.

A separação dos valores em grupos genéticos (Tabela 2) mostrou maior consumo para os animais mestiços E x Z, embora a intensidade deste efeito possa estar, em parte, confundida pela inclusão, nesta categoria, da maioria dos dados relacionados a vacas em lactação.

A semelhança dos valores de consumo entre zebuínos e europeus corrobora os resultados de Rodriguez et al. (1996), que encontraram consumos de matéria seca e de FDN semelhantes entre animais Holandeses e Nelore submetidos a diferentes níveis de concentrado na dieta, discordando, no entanto, dos resultados apresentados por Barcellos et al. (2000), que observaram maior consumo de matéria seca em bovinos holandeses em relação a animais da raça Gir. Estudo recente apontou, no entanto, que animais Nelore selecionados para produção podem apresentar consumo de matéria seca semelhante a animais de raças européias e seus mestiços (Resende et al., 2000).

Os volumosos que constituíam a base das dietas analisadas foram agrupados em três diferentes classes: 1) silagens (milho, sorgo e aveia); 2) fenos; e 3) cana-de-açúcar (bagaço, integral, pontas e sacharina). Fontes de volumosos que não se incluíram dentro desta divisão não foram consideradas. Observou-se pequena superioridade numérica para os consumos de dietas à base de silagens, efeito que, a exemplo do descrito para grupo genético, pode ser em parte atribuído à concentração de dados oriundos de vacas em lactação. Por outro lado, esperar-se-iam menores valores de consumo relacionados à dietas com canade-açúcar, face aos altos valores de fração fibrosa não disponível à degradação ruminal e, conseqüente-

Tabela 2 - Médias para consumo médio diário de matéria seca (CMS) e de FDN (CFDN) (g/kg PV), em função de diferentes variáveis categóricas

Table 2 - Means of the average daily intake of dry matter (DMI) and NDF (NDFI) ( $g / k g L W)$, according to the different categorical variables

\begin{tabular}{|c|c|c|c|c|c|c|}
\hline \multirow[b]{2}{*}{$\begin{array}{l}\text { Variável } \\
\text { Variable }\end{array}$} & \multirow[b]{2}{*}{$\begin{array}{c}\text { Categoria } \\
\text { Category }\end{array}$} & \multicolumn{2}{|c|}{$\begin{array}{l}\text { CMS } \\
D M I\end{array}$} & \multicolumn{2}{|c|}{$\begin{array}{l}\text { CFDN } \\
N D F I\end{array}$} & \multirow[b]{2}{*}{$\mathrm{n}$} \\
\hline & & $\begin{array}{c}\text { Média } \\
\text { Mean }\end{array}$ & $\begin{array}{l}\mathrm{EPM}^{1} \\
\text { SEM }^{l} \\
\end{array}$ & $\begin{array}{l}\text { Média } \\
\text { Mean }\end{array}$ & $\begin{array}{l}\mathrm{EPM}^{1} \\
\text { SEM }^{1}\end{array}$ & \\
\hline \multirow{2}{*}{$\begin{array}{l}\text { Categoria animal } \\
\text { Animal categorie }\end{array}$} & Vacas em lactação & 32,57 & 0,587 & 13,24 & 0,399 & 40 \\
\hline & $\begin{array}{l}\text { Lactations cows } \\
\text { Bovinos em crescimento e terminação } \\
\text { Growing and finishing cattle }\end{array}$ & 21,24 & 0,348 & 10,51 & 0,313 & 141 \\
\hline \multirow[t]{2}{*}{$\begin{array}{l}\text { Grupo genético } \\
\text { Genetic group }\end{array}$} & $\begin{array}{l}\text { Europeu }(\mathrm{E}) \\
\text { European }(E)\end{array}$ & 23,02 & 0,998 & 10,46 & 0,868 & 33 \\
\hline & $\begin{array}{l}\text { Mestiço ExZ } \\
\text { Crossbred ExZ } \\
\text { Zebuíno (Z) } \\
\text { Zebu }(Z)\end{array}$ & 21,51 & $\begin{array}{l}0,596 \\
0,860\end{array}$ & 11,54 & 0,490 & 26 \\
\hline \multirow[t]{3}{*}{$\begin{array}{l}\text { Alimento volumoso } \\
\text { Roughage }\end{array}$} & $\begin{array}{l}\text { Feno } \\
\text { Hay }\end{array}$ & 20,22 & 0,462 & 10,06 & 0,435 & 73 \\
\hline & $\begin{array}{l}\text { Silagem } \\
\text { Silage }\end{array}$ & 27,77 & 0,734 & 11,99 & 0,429 & 74 \\
\hline & $\begin{array}{l}\text { Cana-de-açúcar } \\
\text { Sugarcane }\end{array}$ & 22,31 & 1,179 & 11,44 & 0,558 & 18 \\
\hline
\end{tabular}

${ }^{1}$ EPM $=$ erro-padrão da média

1 SEM = standard error of mean.

R. Bras. Zootec., v.32, n.6, p.1763-1777, 2003 (Supl. 1) 
mente, elevado efeito de repleção ruminal da FDN desta forrageira (Pereira et al., 2000). Os valores de consumo semelhantes aos obtidos nas dietas à base de fenos podem ser justificados pelo fato de os níveis de concentrado médios empregados em estudos com cana-de-açúcar serem menos elevados e discrepantes em relação à média geral deste estudo $(13,5 \%) \mathrm{e}$ à grande incidência de fenos de baixa qualidade, com teores médios de FDN superiores a $800 \mathrm{~g} / \mathrm{kg}$ MS e de PB inferiores a $40 \mathrm{~g} / \mathrm{kg}$ MS. A superioridade das silagens em relação à cana-de-açúcar é concordante aos relatos de Furtado et al. (1991).

Ressalta-se, contudo, de forma geral, que os dados relacionados a variáveis categóricas devem ser interpretados com cautela, pois, uma vez expostos descritivamente, não se asseguram inferências populacionais ou elimina-se a ocorrência de vícios ou efeitos de confundimento.

\section{Consumo de matéria seca e de fibra em detergente} neutro avaliado em função de variáveis contínuas

O comportamento descritivo e a equação de regressão entre níveis de NDT e de FDN na dieta são apresentados na Figura 1.

Os dados apresentaram boa coesão em torna da linha representativa dos valores estimados, consequiência do alto nível de correlação entre as variáveis $(r=-0,6006 ; \mathrm{P}<0,0001)$. Este comportamento demonstra a possibilidade de o valor da concentração de FDN indicar, com boa precisão, o nível energético de um alimento/dieta em modelos estáticos de predição de consumo (Mertens, 1994). Devido à alta correlação entre NDT e digestibilidade da matéria orgânica (Valadares et al., 1997), pode-se inferir que relação semelhante seja encontrada sobre este último parâmetro. Comportamento semelhante ao descrito neste trabalho foi relatado por Ladeira et al. (1999), Dias et al. (2000) e Tibo et al. (2000). Diferentemente, Véras et al. (2000) encontraram comportamento quadrático entre as variáveis analisadas.

A boa relação observada, mesmo sendo obtida de diferentes fontes de FDN, corrobora a afirmação de Mertens (1987) de que, embora seja evidente que as características da FDN variem entre fontes de fibra, este componente melhor mensura a distinção entre os componentes alimentares de lenta degradação daqueles solúveis e de rápida degradação.

Dentro desse contexto, salienta-se que, embora seja obtida alta correlação (o que não implica em alta relação causa/efeito), o aumento do conteúdo energético e/ou digestibilidade é também reflexo de efeito substitutivo na composição centesimal dietética, ou seja, envolve não só redução dos componentes de mais lenta digestão, mas também a inclusão de componentes de maior potencial de digestão, normalmente carboidratos não-fibrosos.

A elevação do nível de carboidratos não-fibrosos (CNE) na dieta levou à redução da digestibilidade total da FDN $(r=-0,1631 ; \mathrm{P}=0,0802)$ (Figura 2).

Parte deste efeito parece estar relacionada à ampliação do tempo de colonização (lag time) sobre a fração fibrosa, que reflete negativamente sobre o percentual de desaparecimento da fibra em períodos fixos de tempo após o início da atividade microbiana (Mertens \& Loften, 1980), contribuindo efetivamente para o efeito de enchimento ruminal da FDN (Jung \& Allen, 1995). Por outro lado, variações na digestão da fibra têm sido atribuídas a quedas no $\mathrm{pH}$ ruminal, em função do acúmulo de ácidos graxos voláteis oriundos da fermentação de fontes rapidamente degradáveis de carboidratos (Mould et al., 1983; Russell \& Wilson, 1996). Em adição, Hoover (1986) afirmou que a competição por substratos para o crescimento microbiano pode desfavorecer o crescimento de microrganismos fibrolíticos na presença de carboidratos prontamente degradáveis. A intensidade

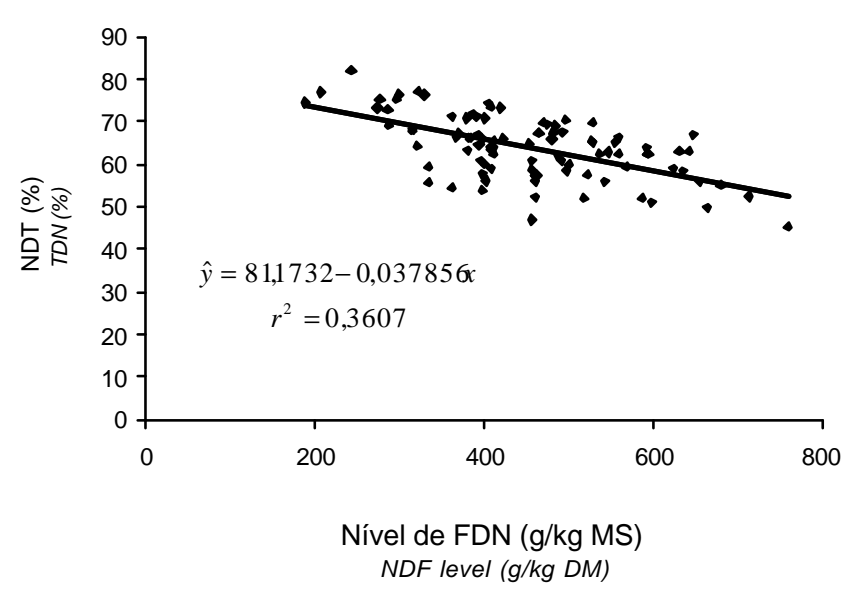

Figura 1 - Comportamento descritivo e equação de regressão para nível de nutrientes digestíveis totais (NDT) (y), em função do nível de fibra em detergente neutro $(x)$ na dieta $(n=95$; $\left.\mathrm{P}_{\text {linear }}=0,0001 ; \mathrm{DP}=5,8404\right)$.

Figure 1 - Descriptive behavior and regression equation for TDN level ( $y$ ), according to the dietary NDFlevel $(x)$ $\left(n=95 ; P_{\text {linear }}=.0001 ; S D=5.8404\right)$. 


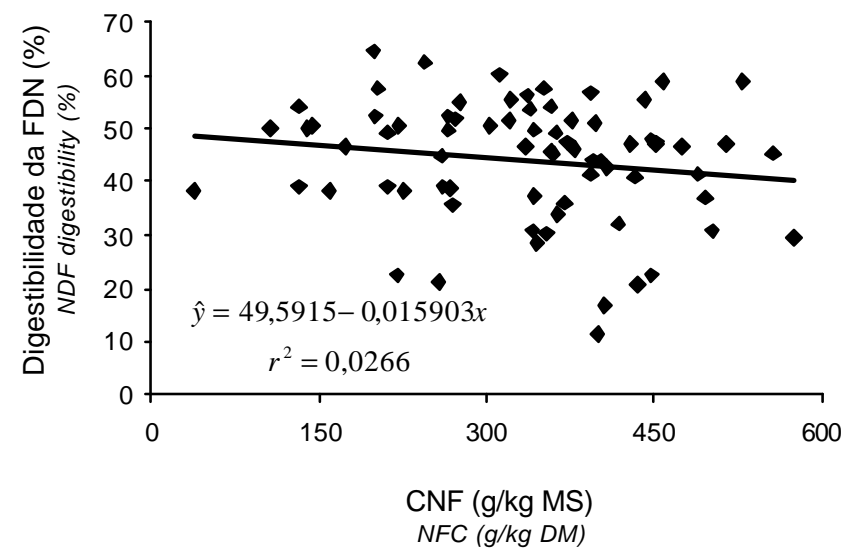

Figura 2 - Comportamento descritivo e equação de regressão para digestibilidade da fibra (y) em detergente neutro, em função do nível de carboidratos não-fibrosos (ÇNF) na dieta $(x)$ $\left(\mathrm{n}=74 ; \mathrm{P}_{\text {linear }}=0,0802 ; \mathrm{DP}=11,11547\right)$.

Figure 2 - Descriptive behavior and regression equation for NDF digestibility $(y)$, according to the dietary nonfibrous carbohydrate (NFC) levels $(x)$ ( $n=74$; $P_{\text {linear }}=.0802 ; S D=11.11547$ ).

destes efeitos pode variar de acordo com a fonte de amido empregada (Tamminga, 1993).

A relação entre consumo e digestibilidade da FDN é apresentada na Figura 3, não sendo observada correlação significativa entre estas variáveis $(\mathrm{P}>0,15)$. Similaridade a este comportamento foi observada sobre o consumo de MS ( $\mathrm{r}=0,0178 ; \mathrm{P}=0,4281 ; \mathrm{n}=106)$.

Os componentes fibrosos representam uma fração significante da dieta dos herbívoros, sendo a produtividade destes animais função de sua habilidade ou capacidade não só de consumir, mas também de digerir esta fração (Allen \& Mertens, 1988). Assim, a digestibilidade da FDN constitui importante parâmetro de qualidade da forragem devido à grande variabilidade na degradação ruminal e sua influência sobre o desempenho animal (Oba \& Allen, 1999).

A interpretação dos efeitos da digestibilidade da FDN sobre o consumo é complexa face à grande variedade de fatores de confundimento. Se duas forragens são comparadas sob diferentes relações volumoso:concentrado, outros fatores dietéticos como digestão ruminal do amido, podem afetar o consumo de MS. Por outro lado, se são comparadas sob relações volumoso:concentrado similares, mas sob diferentes concentrações de FDN, os resultados são confundidos por diferenças no efeito de enchimento ruminal (Oba \& Allen, 1999).

Em uma tentativa para isolar o efeito da digestibilidade da FDN sobre o consumo de MS, procedeu-se à classificação da variável digestibilidade da FDN em três diferentes grupos: $\leq 40 \%$; $>40 \%$ e $\leq$ $50 \%$; e $>50 \%$, conduzindo-se uma análise de variância empregando-se somas de quadrados do tipo III sobre a variável consumo de MS, incluindo variáveis categóricas grupo genético, fonte de volumosos e categoria animal como fatores de controle local, e as covariáveis níveis dietéticos de volumosos e carboidratos não-fibrosos $(\mathrm{n}=70)$. Contudo, nenhum efeito relativo à digestibilidade da FDN foi detectado $(\mathrm{P}=0,8789)$, corroborando a dificuldade de isolamento deste efeito no banco de dados disponível ao estudo.

Em procedimento estatístico semelhante, Oba \& Allen (1999) obtiveram com êxito o isolamento dos efeitos de digestibilidade da FDN e concluíram que estes afetaram positivamente o consumo de MS de vacas em lactação. Estes autores afirmaram, em adição, que efeitos marginais na digestibilidade da fibra podem não ser linearmente relacionados com a resposta animal; uma unidade percentual de acréscimo na digestibilidade da FDN exerça, provavelmente, maior influência em níveis mais baixos de digestibilidade (ex.: 30\%) que em níveis mais elevados (ex.: 60\%).

Em razão de a fibra ser resistente à digestão por

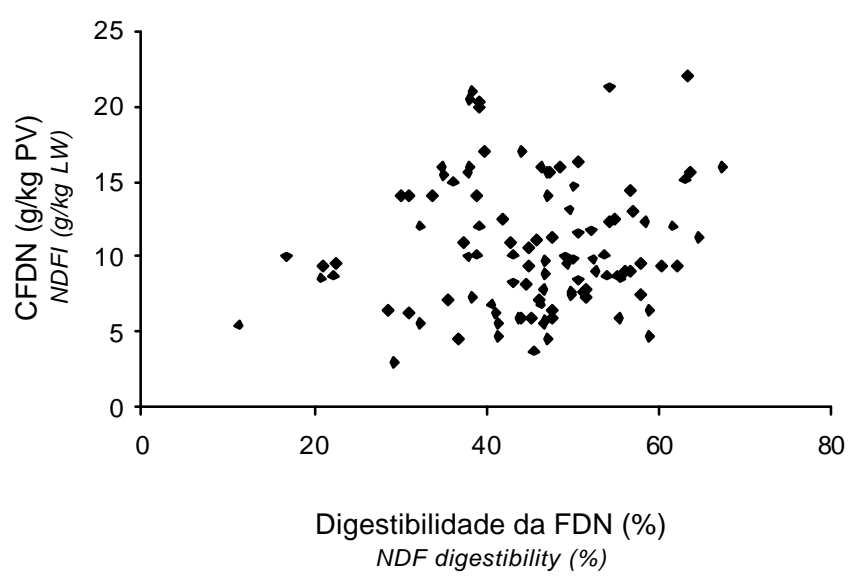

Figura 3 - Comportamento descritivo para consumo de fibra em detergente neutro (CFDN), em função da digestibilidade da FDN dietética (média $=$ 10,$64 ; n=106 ; r=0,0975, P=0,1588 ; E P M=$ $0,4161)$.

Figure 3 - Descriptive behavior for NDF intake (NDFI), according to the dietary NDF digestibility (mean = $10.64 ; n=106 ; r=0.0975, P=.1588 ;$ SEM $=0.4161$ ). 
enzimas de mamíferos, pode-se concluir que entraves sobre a digestão da fibra por microrganismos ruminais sejam fatores limitantes da produtividade dos ruminantes (Allen \& Mertens, 1988). Dentre os substratos envolvidos no metabolismo microbiano, a proteína tem recebido atenção nos trópicos como nutriente limitante (Leng, 1990). Os requerimentos de compostos nitrogenados por microrganismos fibrolíticos podem ser enquadrados em duas formas distintas. Em primeiro lugar, de forma quantitativa, em função do nitrogênio amoniacal disponível no ambiente ruminal, uma vez que microrganismos que degradam carboidratos fibrosos o empregam como substrato para síntese protéica (Russell et al., 1992). Em adição, destaca-se a exigência por ácidos graxos de cadeia ramificada necessários no processo de síntese protéica microbiana, sendo supridos pela deaminação de aminoácidos dietéticos (valina, leucina e isoleucina) (Hoover, 1986).

No entanto, conforme demonstrado na Figura 4, a digestibilidade da FDN não demonstrou relação significativa com o nível de $\mathrm{PB}$ da dieta $(\mathrm{P}=0,1710)$. De forma semelhante ao efeito da digestibilidade sobre o consumo de FDN, realizou-se procedimento de análise de variância sobre a digestibilidade da FDN, empregando-se somas de quadrados tipo III, agrupando-se o nível de PB dietético em três subclasses $(\leq 120$; > 120 e $\leq 140$; e > $140 \mathrm{~g} / \mathrm{kg} \mathrm{MS})$, adicionando-se a covariável nível dietético de FDN

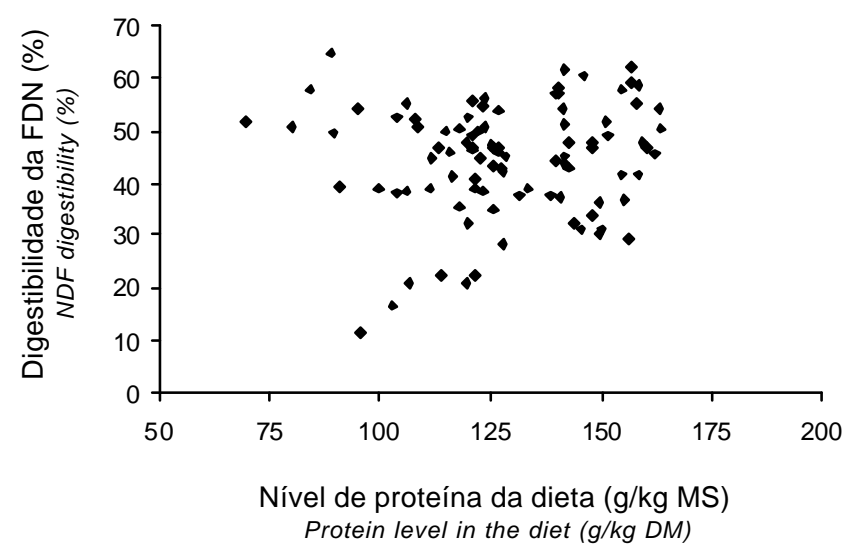

Figura 4 - Comportamento descritivo para digestibilidade da fibra em detergente neutro (y), em função do nível de proteína dietética $(x)$ (média $=44,59 ; n=94 ; r=0,0986, P=0,1710$; $\mathrm{EPM}=1,0912$ ).

Figure 4 - Descriptive behavior for NDF digestibility (y) according to the dietary crude protein level $(x)$ (mean $=44.59 ; n=94 ; r=0.0986, P=.1710 ;$ SEM = 1.0912). (linear e quadrático). Não se obteve, contudo, efeito significativo para diferentes classes de nível protéico ( $\mathrm{P}>0,73)$, novamente demonstrando a dificuldade de avaliação de efeitos envolvendo a digestibilidade da FDN, notadamente sobre grande variedade de dados, como neste estudo.

Contraditoriamente, a elevação do nível protéico dietético refletiu negativamente sobre o consumo de FDN $(\mathrm{P}=0,0050)$ (Figura 5). Este resultado pode ser atribuído ao fato de a relação estimada estar, possivelmente, distorcida por efeitos de confundimento. Salienta-se que os maiores níveis de PB coincidiram com a elevação dos níveis de concentrado na dieta e conseqüente redução dos teores de FDN. Isto é reiterado pela forte correlação negativa obtida entre os níveis de PB e FDN dietéticos $(\mathrm{r}=-0,6785$; $\mathrm{P}<0,0001 ; \mathrm{n}=166$ ). Por outro lado, o consumo de MS foi positivamente correlacionado ao nível dietético de PB ( $r=0,4168 ; \mathrm{P}<0,0001 ; \mathrm{n}=166)$.

Diante do embasamento teórico e de evidências experimentais demonstrando o efeito benéfico da ampliação do fornecimento de PB sobre o consumo e digestão da fibra (DelCurto et al., 1990; Hannah et al., 1991; Valadares et al., 1997; Olson et al., 1999), infere-se que os resultados obtidos não possam ser representativos do sistema biológico em função de elevada influência de efeitos de confundimento sobre o conjunto de dados analisado.

O comportamento descritivo para o consumo de

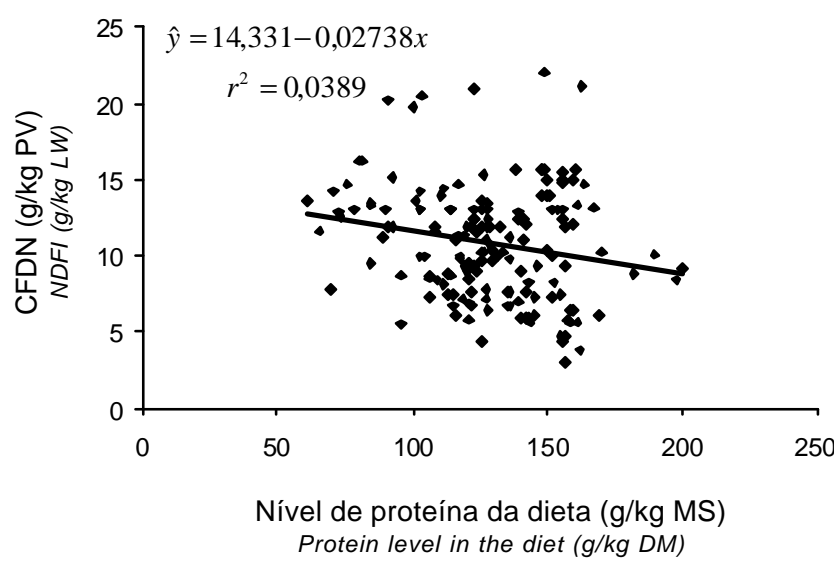

Figura 5 - Comportamento descritivo e equação de regressão para consumo de fibra em detergente neutro (CFDN) (y), em função do nível de proteína bruta $(\mathrm{x})$ na dieta $\left(\mathrm{n}=166\right.$; $\mathrm{P}_{\text {linear }}=$ 0,$0050 ; \mathrm{DP}=3,5801$ ).

Figure 5 - Descriptive behavior and regression equation for NDF intake (NDFI) (y), according to the dietary crude protein level $(x)\left(n=166 ; P_{\text {linear }}=.0050\right.$; $S D=3.5801$ ). 
MS, em função do nível de FDN na dieta, é expresso na Figura 6. Embora relações quadráticas sejam descritas entre estas variáveis (Véras et al., 2000), optou-se pela descrição matemática do perfil de forma bifásica, buscando correspondência às curvas do modelo estático de Mertens (1987).

A descrição inicial do perfil bifásico para o consumo de matéria seca por ruminantes foi realizada por Conrad et al. (1964), empregando como variável regressora a digestibilidade da MS. Estes autores encontraram que melhor ajuste foi obtido quando se procedeu à logaritmização das variáveis dependente e regressora. Dessa forma, optou-se pela adoção do modelo exponencial, conforme a equação:

$$
\mathrm{CMS}=\mathrm{A}_{x} \cdot \exp \left( \pm \mathrm{k}_{x} \cdot \mathrm{FDN}\right)
$$

em que: $\mathrm{CMS}=$ consumo de matéria seca; $\mathrm{A}_{x}=$ intercepto teórico projetado para o nível 0 de FDN na dieta; $\mathrm{k}_{x}=$ taxa fracional de alteração no consumo em função do nível de FDN na dieta; e $\mathrm{X}=$ fases de ajustamento (1 e 2).

Por intermédio de inspeção visual do comportamento dos dados (Figura 6), identificou-se, subjetivamente, a fase de transição para os controles físico e metabólico entre os níveis dietéticos de FDN de 390 a $440 \mathrm{~g} / \mathrm{kg} \mathrm{MS}$, sendo, dessa forma, mantido comum a ambas as fases. Algumas observações discrepantes (outliers) foram eliminadas por inspeção visual dos resíduos ordinários após o ajustamento inicial. Em-

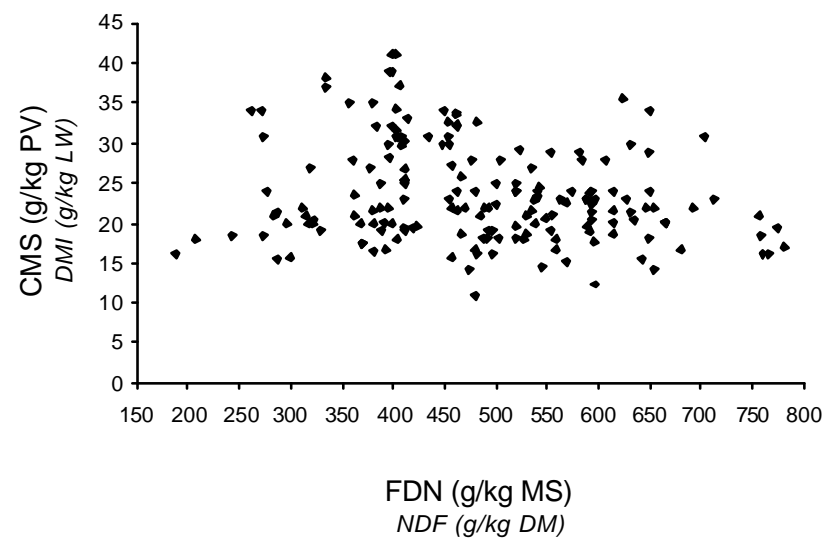

Figura 6 - Comportamento descritivo para consumo de matéria seca (CMS), em função da FDN dietética (média $=23,74 ; n=181 ; r=-0,2267$, $\mathrm{P}=0,0009$; $\mathrm{EPM}=0,4608$ ).

Figure 6 - Descriptive behavior for dry matter intake (DMI), according to the dietary NDF level ( $m e a n=23.74 ; n=181 ; r=-0.2267, P=.0009$; $S E M=0.4608)$.

R. Bras. Zootec., v.32, n.6, p.1763-1777, 2003 (Supl. 1) pregou-se processo de logaritmização para obtenção de estimativas iniciais, sendo o ajustamento realizado por intermédio do processo iterativo de Gauss-Newton (Souza, 1998). As equações ajustadas são mostradas nas Figuras 7 e 8.

Observou-se, por intermédio das taxas fracionais, que a fase relacionada ao controle metabólico do consumo (Fase 1; Figura 7) mostrou-se mais sensível a alterações no nível de FDN na dieta.

A partir das estimativas obtidas, procedeu-se à identificação do ponto de consumo máximo de matéria seca (PCM), determinado pela interseção das curvas (Mertens, 1987, 1994). Para tanto, empregou-se a equação:

$$
P M C=\left(\ln A_{1}-\ln A_{2}\right) /\left(k_{1}+k_{2}\right)
$$

em que: $\mathrm{A}_{1} ; \mathrm{A}_{2} ; \mathrm{k}_{1} ; \mathrm{e}_{2}$ como definidos anteriormente.

O ponto máximo de consumo de MS $(29,5036 \mathrm{~g} / \mathrm{kg} \mathrm{PV})$ foi observado na concentração de 404,41 g FDN/kg MS. A projeção deste valor indica consumo aproximado de FDN de 11,93 g/kg PV, o qual, em primeira instância, mostra-se similar àquele de $12 \mathrm{~g} / \mathrm{kg}$ PV proposto pelo modelo estático bifásico como máximo consumo de FDN por vacas em lactação (Mertens, 1987).

Embora as teorias física e fisiológica da regulação do consumo sejam extensivamente documentadas e comumente aceitas, a aplicação destas dentro do

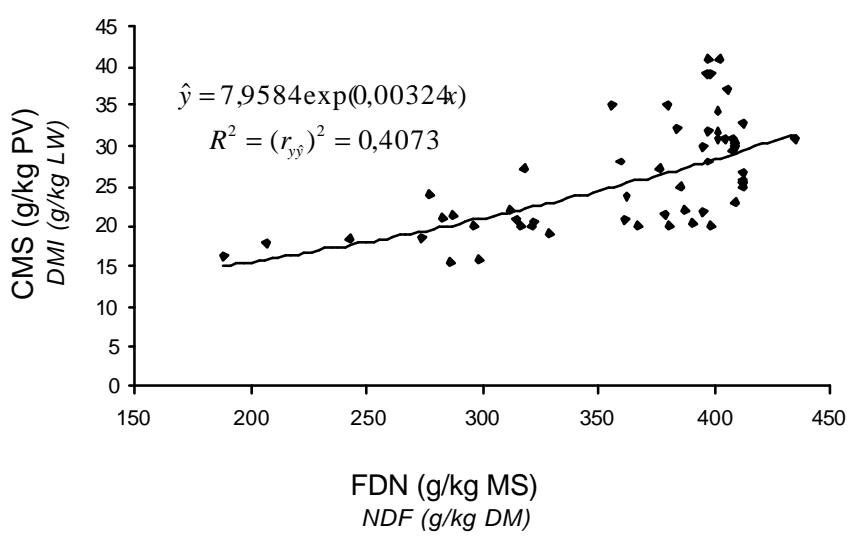

Figura 7 - Comportamento descritivo e equação de regressão não-linear descritiva para consumo de matéria seca (CMS) (y), em função do nível de fibra em detergente neutro da dieta (FDN) (x) - FASE 1 ( $n=56$; Desvio-padrão assintótico $=5,2078$ ).

Figure 7 - Descriptive behavior and non-linear regression equation for dry matter intake (DMI) (y), according to the dietary NDF level $(x)$ - PHASE 1 ( $n=56$; Asymptotic standard deviation $=5.2078)$. 


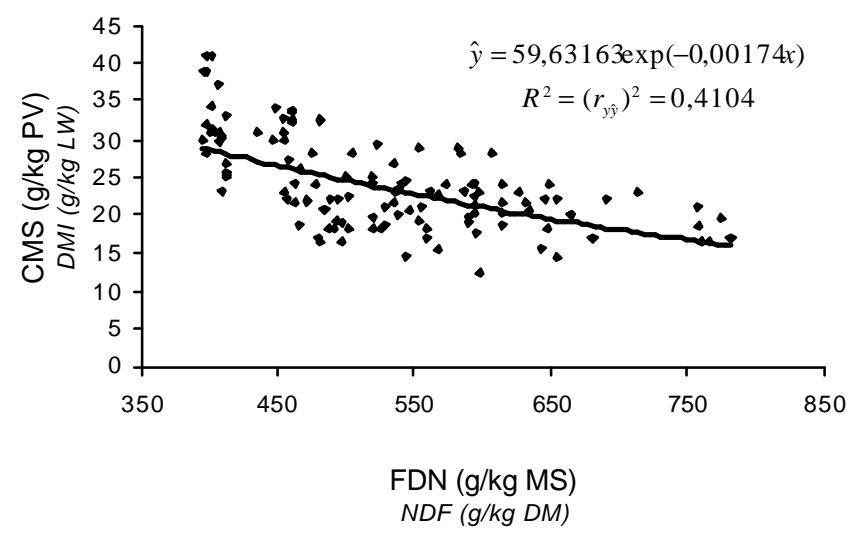

Figura 8 - Comportamento e equação de regressão não-linear descritiva para consumo de matéria seca $(\mathrm{CMS})(\mathrm{y})$, em função do nível de fibra em detergente neutro da dieta (FDN) (x) FASE 2 ( $n=127$; Desvio-padrão assintótico = 4,5992).

Figure 8 - Descriptive behavior and non-linear regression equation for dry matter intake (DMI) ( $y)$, according to the dietary NDF level $(x)$ - PHASE $2(n=127$; Asymptotic standard deviation $=4.5992)$.

modelo estático de predição do consumo baseia-se em pressuposições que exigem pesquisas adicionais e refinamentos. Estas pressuposições, segundo Mertens (1987), são: 1) FDN pode ser empregada para representar adequadamente o efeito do enchimento; 2) a capacidade de enchimento diária é relativamente constante; e 3) a implementação estática das teorias representa adequadamente a natureza dinâmica dos mecanismos da regulação do consumo.

A forte relação entre o consumo e digestibilidade encontrada em ruminantes e a influência negativa dos resíduos não digeridos sobre a capacidade do consumo são contrárias à situação encontrada em nãoruminantes, em que fatores fisiológicos, incluindo produção de calor, glicemia e relações teciduais parecem afetar mais intensamente os estímulos de saciedade (Conrad et al., 1964).

A forte correlação entre a FDN e a fase de regulação física do consumo se dá principalmente em virtude do alto volume ocupado pela fração da parede celular das forragens (Mertens, 1994), bem como às suas características de baixa densidade e de degradação mais lenta quando comparada ao conteúdo celular (Van Soest, 1994; NRC, 2001). A distensão no compartimento rúmen-reticular provocada pelo enchimento estimula receptores na camada muscular localizados, principalmente, em nível de retículo e saco cranial (Allen, 1996, 2000), em que mecanoreceptores são excitados por estímulos mecânicos e químicos e tensoreceptores respondem à distensão em si (Allen, 2000), estimulando o final do período de alimentação.

Para melhor entendimento dos efeitos de enchimento obteve-se equação de regressão para os consumos de FDN correspondentes às estimativas de consumos de MS obtidos por intermédio da equação de regressão exponencial ajustada sobre a Fase 2 (Figura 9) $(y=[59,63163 \exp (-0,00174 x)] x ;$ em que $\mathrm{x}=$ nível dietético de FDN), em função do nível dietético de FDN. Observou-se comportamento quadrático, com ponto de máxima resposta na concentração dietética de FDN de 592,2 g/kg MS, com projeção de consumo de 12,56 g FDN/kg PV.

A união das pressuposições 2 e 3 , citadas anteriormente, denota o fato de a adoção do modelo estático de predição de consumo (Mertens, 1987) assumir que o consumo de FDN, durante a fase de controle físico, ser constante, o que contraria os resultados aqui demonstrados. Reflexo deste comportamento foi apresentado por Rayburn \& Fox (1993), que obtiveram melhor nível de agregação entre consumos de vacas em lactação preditos e observados pelo modelo estático ao empregarem consumo variado de FDN, em detrimento ao valor fixo de $12 \mathrm{~g} / \mathrm{kg}$ PV.

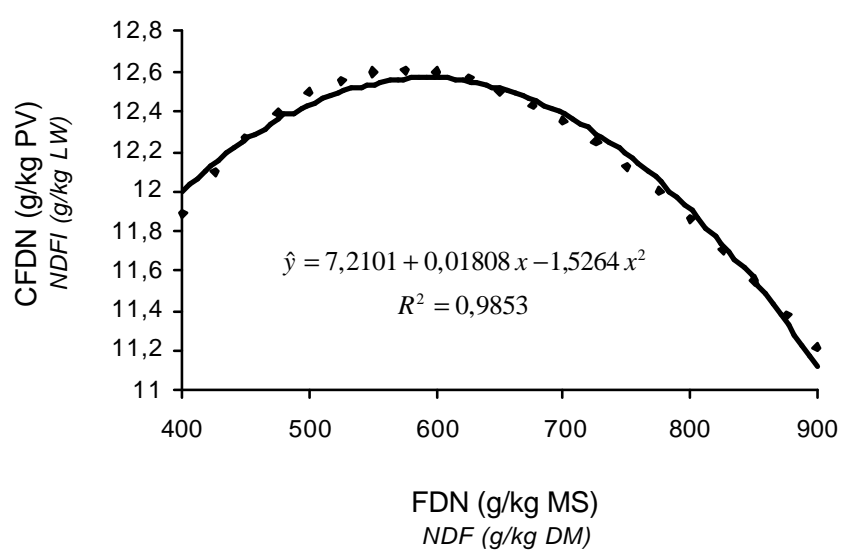

Figura 9 - Consumo de fibra em detergente neutro (FDN) $(y)$, em função do nível de FDN na dieta $(x)$ (projeção de valores estimados por intermédio da equação descritiva não-linear FASE 2).

Figure 9 - Neutral detergent fiberintake (y), according to the dietary NDF level $(x)$ (projection of values estimated by non-linear descriptive equation PHASE 2). 
Em adição, observou-se a divergência entre os valores de máximo consumo de FDN e de MS. Segundo Forbes (1996), efeitos interativos entre os mecanismos físico e fisiológicos podem ser observados, em detrimento de uma caracterização bifásica da regulação do consumo. Mbanya et al. (1993), ao avaliarem o consumo de vacas em lactação tratadas com infusão ruminal de acetato e butirato, na forma de sais de sódio, e/ou ocupação de parte do volume ruminal por um balão inerte, constataram que a redução no consumo ocorreu mais intensamente com a aplicação dos fatores em conjunto, quando comparada à soma de seus efeitos isolados.

Dessa forma, um mecanismo com interações entre fatores fisicos e metabólicos pode estar envolvido na ampla variação de dietas utilizadas por ruminantes, não havendo regulação simplesmente metabólica em um ponto onde o controle por enchimento não seria mais uma limitação ao total de energia ingerida (Egan, 1970, citado por Mbanya et al., 1993). Segundo Allen (1996), a adoção de um ponto de transição, proposta inicialmente por Conrad et al. (1964), seria, principalmente, uma simplificação matemática conveniente, pois o efeito de enchimento e seus estímulos diminuem gradualmente com a ampliação da digestibilidade. Assim, o comportamento encontrado indica que, possivelmente, a transição entre as fases de dominância de fatores metabólicos e físicos possa ser melhor representada por um intervalo em que se observaria forte interação entre os mecanismos.

Face ao comportamento observado (Figura 9), procedeu-se à investigação do consumo de FDN em função do nível de volumosos nas dietas, o qual é expresso na Figura 10. A avaliação de dispersão dos dados indicou comportamento ascendente com tendência de estabilização em níveis elevados de volumosos na dieta. Dessa forma, para descrição matemática deste perfil, optou-se pelo emprego da equação logística:

$$
C F D N=A /[1+B \exp (-C x)]
$$

em que: $\mathrm{CFDN}=$ consumo de FDN; $\mathrm{A}=$ assíntota para o consumo de FDN; B = parâmetro de ajustamento escalar para o intercepto; $\mathrm{C}=$ taxa fracional média de alteração no consumo de FDN; e $\mathrm{x}=$ nível de volumoso na dieta.

Segundo a função expressa na Figura 10, projeta-se em 12,9252 $\pm 1,1351 \mathrm{~g}$ FDN $/ \mathrm{kg}$ MS o intervalo de confiança assintótico (ICA), a 95\% de probabilidade, para a estimativa do parâmetro "A". A projeção do nível de volumosos na dieta necessário para estabelecer o consumo estimado referente ao limite inferior do $\mathrm{ICA}_{95 \%}$ (A), ponto a partir do qual existe similaridade estatística ao valor assintótico, coincide com $64,05 \%$. Frente ao comportamento de intervalo de transição regulatória indicado pela Figura 9, pode-se especular que este nível, dentro do conjunto de dados analisados, determine o início da predominância de mecanismos físicos de regulação do consumo, dentro do contexto de interação com os mecanismos metabólicos.

Embora se obtendo ajustamento coerente da função logística ao conjunto de dados expressos na Figura 10, observa-se grande nível de dispersão dos valores observados de consumo de FDN em torno da linha de projeção de estimativas. Desta forma, com objetivo de melhorar o entendimento deste comportamento, procedeu-se à avaliação do consumo de FDN em intervalos de níveis de volumosos na dieta (Figura 11). Ressalta-se que nenhuma inferência pode ser realizada em valores inferiores a $20 \%$ de volumosos, em virtude de escassez de dados localizados neste intervalo.

Constatou-se elevação linear $(\mathrm{P}<0,01)$ do consumo de FDN, em função da ampliação do nível de volumosos nos intervalos $21-40 \%$ e $41-60 \%$, havendo, contudo, estabilidade dentro dos intervalos superiores.

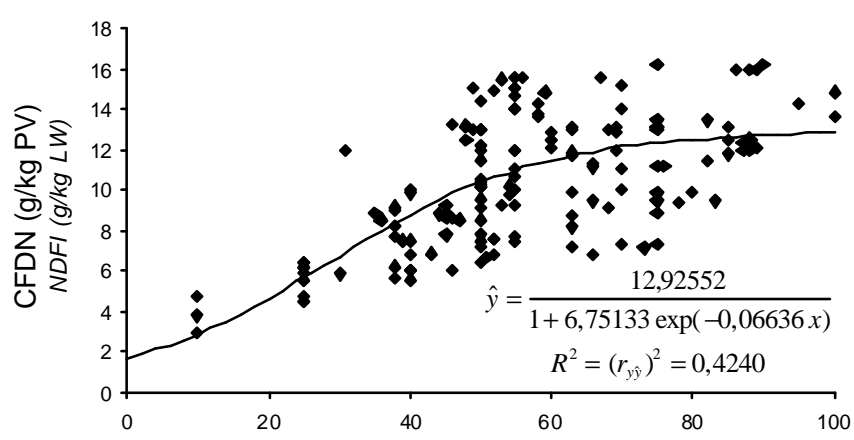

Nível de volumoso (\%)

Forage level (\%)

Figura 10 - Comportamento descritivo e equação de regressão não-linear para consumo de fibra em detergente neutro (CFDN) (y), em função do nível de alimentos volumosos na dieta $(x)$ $(n=156$; Desvio-padrão assintótico $=30,0178)$.

Figure 10 - Descriptive behavior and non-linear regression equation for NDF intake (NDFI) (y), according to the dietary forage level $(x)(n=156$; asymptotic standard deviation $=30.0178)$. 

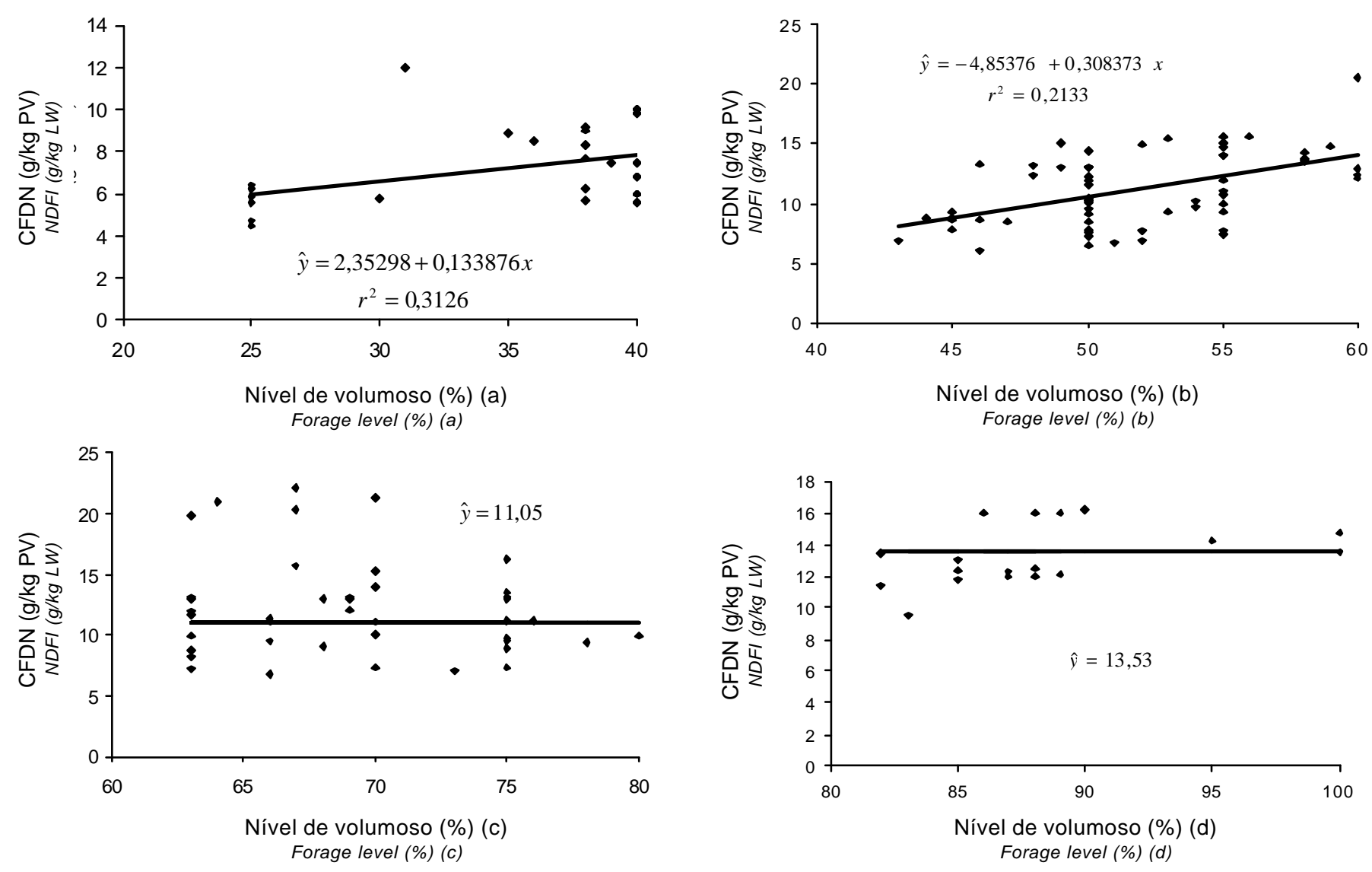

Figura 11 - Comportamento descritivo e equação de regressão para consumo de fibra em detergente neutro (CFDN) (y), em função do nível de alimentos volumosos na dieta $(x)$. $(a)=21-40 \%\left(n=28 ; P_{\text {linear }}=0,0010\right.$; $\mathrm{DP}=1,3345) ;(b)=41-60 \%\left(n=69 ; P_{\text {linear }}=0,0001 ; D P=2,4961\right) ;(c)=61-80 \%(n=37 ; E P M=0,4105)$; $(d)=81-100 \%(n=17 ; E P M=0,4109)$.

Figure 11 - Descriptive behavior and regression equations for NDF intake (NDFI) (y), according to the dietary forage level ( $x$ ). (a) $=21-40 \%\left(n=28 ; P_{\text {linear }}=.0010 ; S D=1.3345\right) ;(b)=41-60 \%\left(n=69 ; P_{\text {linear }}=.0001 ; S D=2.4961\right) ;(c)=61-80 \%$ $(n=37 ;$ SEM $=0.4105) ;(d)=81-100 \%(n=17 ;$ SEM $=0.4109)$.

Observou-se consumo médio de FDN de $13,53 \mathrm{~g} / \mathrm{kg}$ PV no intervalo $81-100 \%$ (Figura 11-d), cujas projeções dos limites do intervalo de confiança, a $95 \%$ de probabilidade $( \pm 0,87 \mathrm{~g} / \mathrm{kg} \mathrm{PV})$ o coloca em patamar estatisticamente superior $(\mathrm{P}<0,05)$ à média de $12 \mathrm{~g} / \mathrm{kg}$ PV proposta por Mertens (1987).

Consumos de FDN iguais ou superiores a este valor são comumente encontrados em vacas lactantes (Araújo et al., 1995; Malafaia et al., 1996; Mayer et al., 1997; Suárez Lodoño et al., 1997) e bovinos em crescimento alimentados com baixos níveis de concentrado na dieta (Ferreira et al., 1999; Miranda et al., 1999) ou volumosos de baixa qualidade (Oliveira et al., 1991; Gomes et al., 1994; Peixoto et al., 1994a). A ocorrência de valores nestes patamares pode ser visualizada na Figura 12.

Waldo (1986), ao comparar o consumo de gramíneas e leguminosas, em níveis semelhantes de digestibilidade, verificou que, embora o consumo de gramíneas tenha sido inferior, observou, para estas, maior conteúdo do trato gastrintestinal, concluindo que o limite físico do consumo é elástico. Segundo Mertens (1994), a capacidade do estômago pode ser modificada por respostas fisiológicas, dentro de certos limites, por hipertrofia de órgãos ou redução nas constrições associadas com depósitos internos de tecidos adiposos, para se alcançar um balanço entre estímulo de distensão e desempenho animal.

Segundo Allen (2000), embora a densidade inicial 
dos alimentos seja relacionada ao teor de FDN, o efeito de enchimento está também relacionado intimamente aos fatores que afetam as cinéticas de digestão e trânsito no compartimento ruminal.

A medida de repleção ruminal dos constituintes fibrosos de um alimento permite, de forma conjunta, avaliar os efeitos de interação das cinéticas de trânsito e digestão sobre a capacidade de enchimento no compartimento ruminal. A mensuração parcial deste efeito atribui alto percentual à fração indigestível da fibra (Vieira et al., 1997), a qual parece ser mais elevada em forrageiras tropicais. Sniffen et al. (1992) propuseram que a fração indigestível da parede celular poderia ser estimada pela multiplicação do teor de lignina pelo fator 2,4. No entanto, em recente estudo conduzido em condições tropicais foram observados fatores variando de 3,3 a 5,2 (Vieira et al., 2000), o que indica maior interação dos compostos fenólicos sobre a matriz da parede celular, gerando menor degradação potencial.

Por outro lado, Schettini et al. (1999), ao introduzirem material inerte, na forma de bolas de tênis, no rúmen de novilhos, obtiveram massa total residente no ambiente ruminal de 11,5, 19,9 e 28,3 kg MS com a adição de $0,7,25$ e 14,5 L, respectivamente, o que mostra claramente a plasticidade do ambiente ruminal. Em adição, o conteúdo ruminal isento do material inerte foi 11,5, 10,3 e 9,1 kg MS, para os mesmos tratamentos, o que demonstra efeito percentual menor que o observado sobre o conteúdo total, indicando certo

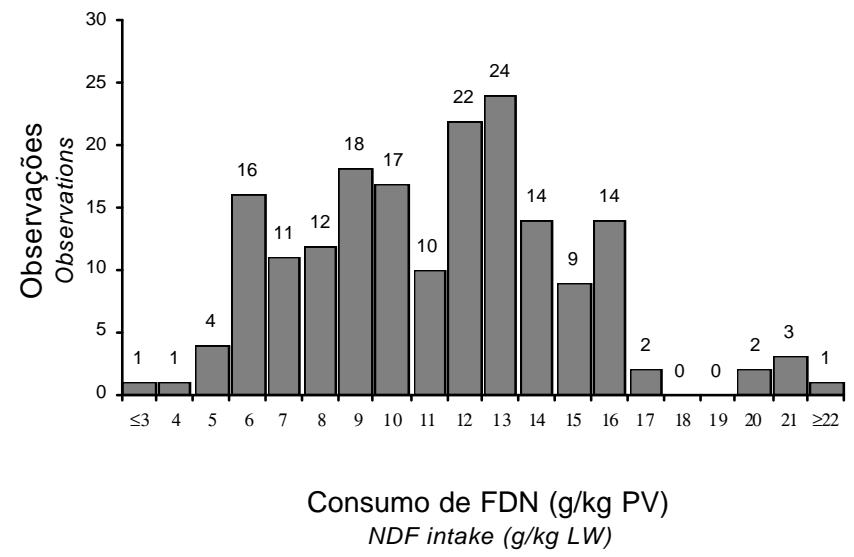

Figura 12 - Histograma para consumo de fibra em detergente neutro.

Figure 12 - Histogram for neutral detergent fiber intake. grau de resposta adaptativa a resíduos indigestíveis.

Animais manejados em condições de pastejo possuem elevada possibilidade de seleção da porção de forragem da dieta, levando a maior digestibilidade e qualidade nutricional do material ingerido em relação ao total disponível (Gomes Jr. et al., 2001). Avaliações do consumo de FDN por animais mantidos nestas condições relataram consumos de FDN superiores a $15 \mathrm{~g} / \mathrm{kg}$ PV para vacas em lactação em pastagens temperadas (Vazquez \& Smith, 2000) e a $16 \mathrm{~g} / \mathrm{kg}$ PV para bovinos em crescimento em pastagens com forrageira tropical (Detmann et al., 1999).

Estas evidências mostram que o nível de FDN indigestível na dieta pode implementar e melhor suportar as estimativas de consumo por bovinos em regiões tropicais, se aplicado em conjunto ao nível de FDN dietético.

\section{Conclusões}

A estimação do consumo de MS, por intermédio do modelo estático bifásico, em bovinos alimentados com forrageiras tropicais pode incorrer em erro devido à inconstância do consumo de FDN durante a fase atribuída ao controle físico do consumo e, pelo fato de, possivelmente, a transição para a fase de controle metabólico ser representada por um intervalo, e não especificamente por um ponto de inversão de mecanismos regulatórios.

A predominância de mecanismos físicos de regulação do consumo é estabelecida com a elevação dos níveis de volumosos na dieta. Neste aspecto, possíveis interações com a fração indigestível da FDN podem ditar a plasticidade do limite físico de consumo, sendo esta, possivelmente, uma medida a ser incorporada em modelos para estimação do consumo voluntário de matéria seca.

Ressalta-se que as estimativas aqui apresentadas não devem ser interpretadas como valores absolutos, em virtude da grande variação nas condições experimentais dos dados analisados, mas sim, consideradas como indicadores de tendência de comportamento.

\section{Literatura Citada}

ALLEN, M.S. Physical constraints on voluntary intake of forages by ruminants. Journal of Animal Science, v.74, n.9, p.3063-3075, 1996.

ALLEN, M.S. Effects of diet on short-term regulation of feed intake by lactating dairy cattle. Journal of Dairy Science, v.83, n.7, p.1598-1624, 2000. 
ALLEN, M.S.; MERTENS, D.R. Evaluating constraints on fiber digestion by rumen microbes. Journal of Nutrition, v.118, n.1, p.261-270, 1988.

ARAÚJO, G.G.L.; COELHO DA SILVA, J.F.; VALADARES FILHO, S.C. et al. Efeito da degradabilidade da proteína sobre consumo e digestão da matéria seca, matéria orgânica e carboidratos estruturais em vacas lactantes. Revista da Sociedade Brasileira de Zootecnia, v.24, n.3, p.371-381, 1995.

ARAÚJO, G.G.L.; COELHO DA SILVA, J.F.; VALADARES FILHO, S.C. et al. Consumo e digestibilidade total dos nutrientes de dietas contendo diferentes níveis de volumosos em bezerros. Revista Brasileira de Zootecnia, v.27, n.2, p.345-354, 1998.

BARCELOS, A.F.; PAIVA, P.C.A.; VON TIESENHAUSEN, I.M.E.V. et al. Desempenho de novilhos de três grupos genéticos em confinamento, recebendo diferentes níveis de casca de café no concentrado. In: REUNIÃO ANUAL DA SOCIEDADE BRASILEIRA DE ZOOTECNIA, 37., 2000, Viçosa, MG. Anais... Viçosa, MG: Sociedade Brasileira de Zootecnia, 2000. CD-ROM.

BÜRGER, P.J.; PEREIRA, J.C.; COELHO DA SILVA, J.F. et al. Consumo e digestibilidades aparente total e parcial em bezerros holandeses alimentados com dietas contendo diferentes níveis de concentrado. Revista Brasileira de Zootecnia, v.29, n.1, p.206-214, 2000.

CALDAS NETO, S.F.; ZEOULA, L.M.; BRANCO, A.F. et al. Mandioca e resíduos das farinheiras na alimentação de ruminantes: digestibilidade total e parcial.Revista Brasileira de Zootecnia, v.29, n.6, p.2099-2108, 2000(Suplemento 1).

CARDOSO, R.C.; VALADARES FILHO, S.C.; COELHO DA SILVA, J.F. et al. Consumo e digestibilidades aparentes totais e parciais de rações contendo diferentes níveis de concentrados em novilhos F1 limousin X nelore. Revista Brasileira de Zootecnia, v.29, n.6, p.1832-1842, 2000.

CARVALHO, A.U.; VALADARES FILHO, S.C.; COELHO DA SILVA, J.F. et al. Níveis de concentrado em dietas de zebuínos: 1.Consumo e digestibilidade aparente. Revista Brasileira de Zootecnia, v.26, n.5, p.986-995, 1997.

CASTILLO, A.M.; VALADARES FILHO, S.C.; COELHO DA SILVA, J.F. et al. Efeito da cecolectomia em bezerros com anastomose íleoretal sobre o consumo voluntário de matéria seca, a digestibilidade aparente de nutrientes e a disponibilidade aparente de minerais. Revista da Sociedade Brasileira de Zootecnia, v.22, n.1, p.81-98, 1993.

CONRAD, H.R.; PRATT, A.D.; HIBBS, J.W. Regulation of feed intake in dairy cows. I. Change in importance of physical and physiological factors with increasing digestibility. Journal of Dairy Science, v.47, n.1, p.54-62, 1964.

DelCURTO, T.; COCHRAN, R.C.; CORAH, L.R. et al. Supplementation of dormant Tallgrass-Prarie forage: I. Influence of varying supplemtnal protein and(or) energy levels on forage utilization characteristics of beef steers in confinement. Journal of Animal Science, v.68, n.2, p.515-531, 1990.

DERESZ, F.; FERNANDES, A.M.; MATTOS, L.L. et al. Utilização da soja crua na alimentação de vacas leiteiras de alta produção. Revista da Sociedade Brasileira de Zootecnia, v.25, n.1, p.113-124, 1996.

DETMANN, E.; PAULINO, M.F.; ZERVOUDAKIS, J.T. et al. Suplementação de novilhos mestiços no período das águas: 1 . Consumo e taxa de passagem. In: REUNIÃO ANUAL DA SOCIEDADE BRASILEIRA DE ZOOTECNIA, 36, Porto Alegre. Anais... Porto Alegre: Sociedade Brasileira de
Zootecnia, 1999. CD-ROM.

DIAS, H.L.C.; VALADARES FILHO, S.C.; COELHO DA SILVA, J.F. et al. Consumo e digestões parciais e totais em novilhos F1 Limousin X Nelore alimentados com dietas contendo cinco níveis de concentrado.Revista Brasileira de Zootecnia, v.29, n.2, p.545-554, 2000.

DULPHY, J.P.; DEMARQUILY, C. The regulation and prediction of feed intake in ruminants in relation to feed characteristics. Livestock Production Science, v.39, n.1, p.1-12, 1994.

DUTRA, A.R.; QUEIROZ, A.C.; PEREIRA, J.C. et al. Efeitos dos níveis de fibra e das fontes de proteína sobre o consumo e digestão dos nutrientes em novilhos. Revista Brasileira de Zootecnia, v.26, n.4, p.787-796, 1997.

FERREIRA, M.A.; VALADARES FILHO, S.C.; COELHO DA SILVA, J.F. et al. Consumo, conversão alimentar, ganho de peso e características de carcaça de bovinos F1 simental X nelore. Revista Brasileira de Zootecnia, v.28, n.2, p.343$351,1999$.

FONSECA, C.E.M.; VALADARES FILHO, S.C.; COELHO DA SILVA, J.F. et al. Utilização de dejetos de suínos in natura na alimentação de bovinos. Revista Brasileira de Zootecnia, v.26, n.1, p.164-170, 1997.

FORBES, J.M. Integration of regulatory signals controlling forage intake in ruminants. Journal of Animal Science, v.74, n.10, p.3029-3035, 1996.

FURTADO, D.A.; CAMPOS, J.; COELHO DA SILVA, J.F. et al. Farelo de trigo como suplemento energético-protéico para a cana-de-açúcar (Sacharum oficinarum L.) e silagem de milho. Revista da Sociedade Brasileira de Zootecnia, v.20, n.3, p.209-217, 1991.

GOMES, B.V.; QUEIROZ, A.C.; FONTES, C.A.A. et al. Estudo das características físico-químicas de fenos e palha. I. Efeitos sobre a ingestão, digestibilidade aparente e taxa de passagem da matéria seca, pH e concentração de amônia ruminal. Revista da Sociedade Brasileira de Zootecnia, v.23, n.3, p.352-365, 1994.

GOMES JR., P.; PAULINO, M.F.; DETMANN, E. et al. Avaliação qualitativa de três métodos de amostragem de dieta em pastagens de capim-braquiária. In: REUNIÃO ANUAL DA SOCIEDADE BRASILEIRA DE ZOOTECNIA, 38., 2001, Piracicaba.Anais...Piracicaba: Sociedade Brasileira de Zootecnia, 2001. p.1165-1136.

HANNAH, S.M.; COCHRAN, R.C.; VANZANT, E.S. et al. Influence of protein supplementation on site and extent of digestion, forage intake, and nutrient flow characteristics in steers consuming dormant Bluestem-Range forage. Journal of Animal Science, v.69, n.8, p.2624-2633, 1991.

HOOVER, W.H. Chemical factors involved in ruminal fiber digestion. Journal of Dairy Science, v.68, n. 1, p.40-44, 1986.

JUNG, H.G.; ALLEN, M.S. Characteristics of plant cell walls affecting intake and digestibility of forages by ruminants. Journal of Animal Science, v.73, n.9, p.2774-2790, 1995.

LADEIRA, M.M.; VALADARES FILHO, S.C.; COELHO DA SILVA, J.F. et al. Consumo e digestibilidades aparentes totais e parciais de dietas contendo diferentes níveis de concentrados em novilhos nelore. Revista Brasileira de Zootecnia, v.28, n.2, p.395-403, 1999.

LENG, R.A. Factors affecting the utilization of "poor-quality" forages by ruminants particularly under tropical conditions. Nutrition Research Review, v.3, n.1, p.277-303, 1990.

LUDOVICO, A.; MATTOS, W.R.S. Avaliação de dietas à base de cana-de-açúcar (Saccharum officinarum L.) e diferentes 
níveis de semente de algodão (Gossypum hirsitum L.). Revista Brasileira de Zootecnia, v.26, n.2, p.403-410, 1997.

MALAFAIA, P.A.M.; VALADARES FILHO, S.C.; COELHO DA SILVA, J.F. et al. Sebo bovino em rações para vacas em lactação: 1. Consumo dos nutrientes, produção e composição do leite. Revista da Sociedade Brasileira de Zootecnia, v.25, n.1, p.153-163, 1996.

MARQUES, J.A.; PRADO, I.N.; ZEOULA, L.M. et al. Avaliação da mandioca e seus resíduos industriais em substituição ao milho no desempenho de novilhas confinadas. Revista Brasileira de Zootecnia, v.29, n.5, p.1528-1536, 2000.

MARTINS, A.S.; PRADO, I.N.; ZEOULA, L.M. et al. Digestibilidade aparente de dietas contendo milho ou casca de mandioca como fontes energéticas e farelo de algodão ou levedura como fontes protéicas em novilhas. Revista Brasileira de Zootecnia, v.29, n.1, p.269-277, 2000.

MATTOS, L.M.E.; FERREIRA, M.A.; SANTOS, D.C. et al. Associação da palma forrageira (Opuntia ficus indicaIMill) com diferentes fontes de fibra na alimentação de vacas $5 / 8$ holandês-zebu em lactação. Revista Brasileira de Zootecnia, v.29, n.6, p.2128-2134, 2000 (Suplemento 1).

MAYER, L.R.R.; COELHO DA SILVA, J.F.; VALADARES FILHO, S.C. et al. Rações com diferentes teores de proteína degradada no rúmen para vacas em lactação. 1.Consumo, produção e composição do leite. Revista Brasileira de Zootecnia, v.26, n.4, p.813-824, 1997.

MBANYA, J.N; ANIL, M.H.; FORBES, J.M. The voluntary intake of hay and silage by lactating cows in response to ruminal infusion of acetate or propionate, or both, with or without distension of the rumen by a balloon. British Journal of Nutrition, v.69, n.3, p.713-720, 1993.

MERTENS, D.R. Predicting intake and digestibility using mathematical models of ruminal function. Journal of Animal Science, v.64, n.5, p.1548-1558, 1987.

MERTENS, D.R. Regulation of forage intake. In: FAHEY JR., G.C. (Ed.) Forage quality, evaluation and utilization. Winsconsin: American Society of Agronomy, 1994.p.450-493.

MERTENS, D.R. Methods in modelling feeding behaviour and intake in herbivores. Annales Zootechnie, v.45, p.153-164, 1996 (Supplement 1).

MERTENS, D.R.; LOFTEN, J.R. The effect of starch on forage fiber digestion kinetics in vitro. Journal of Dairy Science, v.63, n.9, p.1437-1446, 1980

MIRANDA, L.F.; QUEIROZ, A.C.; VALADARES FILHO, S.C. et al. Desempenho e desenvolvimento ponderal de novilhas leiteiras alimentadas com dietas à base de cana-deaçúcar. Revista Brasileira de Zootecnia, v.28, n.3, p.605613, 1999.

MORA, P.J.G.; LEÃO, M.I.; VALADARES FILHO, S.C. et al. Grãos de soja em rações para vacas lactantes: consumo do $s$ nutrientes, produção e composição do leite. Revista da Sociedade Brasileira de Zootecnia, v.25, n.2, p.369-381, 1996.

MOULD, F.L.; ØRSKOV, E.R.; MANNS., O. Associative effects of mixed feeds. I. Effects of type and level of supplementation and the influence of the rumen $\mathrm{pH}$ on cellulolysis in vivo and dry matter digestion of various roughages. Animal Feed Science and Technology, v.10, n.1, p.15-30, 1983

MYERS, R.H. Classical and modern regression with applications. Boston: PWS-KENT Publishing Co., 1990, 488p.

NATIONAL RESEARCH COUNCIL - NRC. Nutrient requirements of dairy cattle. 7.ed. Washington, D.C.: Academic Press, 2001. 381p.

OBA, M.; ALLEN, M.S. Evaluation of the importance of the digestibillity of neutral detergent fiber from forage: effects on dry matter intake and milk yield of dairy cows. Journal of Dairy Science, v.82, n.3, p.589-596, 1999.

OLIVEIRA, R.L.; PEREIRA, J.C.; SILVA, P.R.C. et al. Consumo, digestibilidade e balanço de nitrogênio em novilhos alimentados com cama de frango e suplementação à base de microbiota ruminal liofilizada. Revista Brasileira de Zootecnia, v.28, n.4, p.831-838, 1999.

OLIVEIRA, R.F.M.; FONTES, C.A.A.; COELHO DA SILVA, J.F. et al. Consumo e digestibilidade de dietas com duas proporções de concentrados fornecidas a bovinos de três grupos genéticos. Revista da Sociedade Brasileira de Zootecnia, v.20, n.5, p.513-522, 1991.

OLSON, K.C.; COCHRAN, R.C.; JONES, T.J. et al. Effects of ruminal administration of supplemental degradable intake protein and starch on utilization of low-quality warm-season grass hay by beef steers. Journal of Animal Science, v.77, p.1016-1025, 1999.

PASCOAL, L.L.; EIFERT, E.C.; RESTLE, J. Nível de proteína bruta para bezerros de corte desmamados aos 66 dias de idade. Revista Brasileira de Zootecnia, v.29, n.5, p.1537-1544, 2000.

PEIXOTO, F.A.; COELHO DA SILVA, J.F.; VALADARES FILHO, S.C. et al. Utilização do complexo ácido graxo-cálcio na dieta de vacas em lactação alimentadas com cana-deaçúcar. Revista da Sociedade Brasileira de Zootecnia, v.23, n.2, p.173-180, 1994a.

PEIXOTO, F.A.; COELHO DA SILVA, J.F.; ROSADO, M. et al. Complexo ácido graxo-cálcio na dieta de vacas em lactação alimentadas com silagem de milho, individualmente ou em grupo. Revista da Sociedade Brasileira de Zootecnia, v.23, n.5, p.763-782, 1994b.

PEREIRA, O.G.; VALADARES FILHO, S.C.; GARCIA, R. et al. Consumo e digestibilidade total e parcial dos nutrientes de dietas contendo cana-de-açúcar sob diferentes formas em bovinos. Revista da Sociedade Brasileira de Zootecnia, v.25, n.4, p.750-762, 1996.

PEREIRA, E.S.; QUEIROZ, A.C.; VALADARES FILHO, S.C. et al. Repleção ruminal da fibra em detergente neutro da canade-açúcar e cama de frango. In: REUNIÃO ANUAL DA SOCIEDADE BRASILEIRA DE ZOOTECNIA, 37., 2000, Viçosa, MG. Anais... Viçosa, MG: Sociedade Brasileira de Zootecnia, 2000. CD-ROM.

PRADO, I.N.; MARTINS, A.S. Efeito da substituição do farelo de algodão pelo farelo de canola no desempenho de novilhas nelore confinadas. Revista Brasileira de Zootecnia, v.28, n.6, p.1390-1396, 1999.

PRADO, I.N.; NASCIMENTO, W.G.; ZEOULA, L.M. Níveis de triticale em substituição ao milho no desempenho zootécnico e digestibilidade aparente de novilhos nelore confinados. Revista Brasileira de Zootecnia, v.29, n.5, p.1545-1552, 2000a.

PRADO, I.N.; PINHEIRO, A.D.; ALCALDE, C.R. et al. Níveis de substituição do milho pela polpa de citrus peletizada sobre o desempenho e características de carcaça de bovinos mestiços confinados. Revista Brasileira de Zootecnia, v.29, n.6, p.2135-2141, 2000b (Suplemento 1).

QUEIROZ, A.C.; BARBOSA, M.A.; RESENDE, F.D. et al. Suplementação da palhada de milho na alimentação d bovinos. 1. Consumo, taxa de passagem da matéria seca, degradaçãoin 
situ da matéria seca e fibra em detergente neutro. Revista Brasileira de Zootecnia, v.27, n.2, p.381-389, 1998.

RABELLO, T.G.; VALADARES FILHO, S.C.; COELHO DA SILVA, J.F. et al. Grão de soja moído na alimentação de vacas em lactação. I. Consumo, produção e composição do leite. Revista da Sociedade Brasileira de Zootecnia, v.25, n.2, p.345-356, 1996.

RAMOS, S.M.; VALADARES FILHO, S.C.; COELHO DA SILVA, J.F. et al. Consumo e digestões totais e parciais dos nutrientes em bovinos cecectomizados. Revista da Sociedade Brasileira de Zootecnia, v.25, n.4, p.794-805, 1996.

RAYBURN, E.B.; FOX, D.G. Variation in neutral detergent fiber intake of holstein cows. Journal of Dairy Science, v.76, n.2, p.544-554, 1993.

RESENDE, F.D.; QUEIROZ, A.C.; FONTES, C.A.A. et al. Rações com diferentes níveis de fibra em detergente neutro na alimentação de bovídeos em confinamento.Revista da Sociedade Brasileira de Zootecnia, v.22, n. 3, p.366-376, 1994.

RESENDE, F.D.; QUEIROZ, A.C.; FONTES, C.A.A. et al. Fibra em detergente neutro versus fibra em detergente ácido na formulação de dietas para ruminantes. Revista da Sociedade Brasileira de Zootecnia, v.24, n.3, p.342-350, 1995.

RESENDE, F.D.; NARDON, R.F.; RAZOOK, A.G. et al. Desempenho e características de carcaça de zebuínos e caracu selecionados para peso aos 378 dias de idade, submetidos a dois níveis de energia na terminação. In: REUNIÃO ANUAL DA SOCIEDADE BRASILEIRA DE ZOOTECNIA, 37., 2000, Viçosa, MG. Anais... Viçosa, MG: Sociedade Brasileira de Zootecnia, 2000. CD-ROM.

RODRIGUES, A.A.; BARBOSA, P.F. Efeito do teor protéico do concentrado no consumo de cana-de-açúcar com uréia e ganho de peso em novilhas em crescimento. Revista Brasileira de Zootecnia, v.28, n.2, p.421-424, 1999.

RODRIGUEZ, L.R.R.; FONTES, C.A.A.; JORGE, A.M. et al. Consumo de rações contendo quatro níveis de concentrado por bovinos holandeses e nelores e bubalinos. Revista da Sociedade Brasileira de Zootecnia, v.25, n.3, p.568-581, 1996.

RUSSELL, J.B.; WILSON, D.B. Why are ruminal cellulolytic bacteria unable to digest cellulose at low $\mathrm{pH}$ ? Journal of Dairy Science, v.79, n.5, p.1503-1509, 1996.

RUSSELL, J.B.; O'CONNOR, J.D.; FOX, D.G. et al. A Net Carbohydrate and Protein System for evaluating cattle diets. I. Ruminal fermentation.Journal of Animal Science, v.70, n.11, p3551-3561, 1992.

SCHETTINI, M.A.; PRIGGE, E.C.; NESTOR, E.L. Influence of mass and volume of ruminal contents on voluntary intake and digesta passage of a forage diet in steers.Journal of Animal Science, v.77, n.7, p.1896-1904, 1999.

SIGNORETTI, R.D.; COELHO DA SILVA, J.F.; VALADARES FILHO, S.C. et al. Consumo e digestibilidade aparente em bezerros da raça holandesa alimentados com dietas contendo diferentes níveis de volumoso. Revista Brasileira de Zootecnia, v.28, n.1, p.169-177, 1999.

SNIFFEN, C.J.; O'CONNOR, J.D.; Van SOEST, P.J. et al. A net carbohydrate and protein system for evaluating cattle diets: II. Carbohydrate and protein availability.Journal of Animal Science, v.70, n.10, p.3562-3577, 1992.
SOUZA, G.S. Introdução aos modelos de regressão linear e não-linear. Brasília: EMBRAPA-SPI, 1998. 505p.

STEEL, R.G.; TORRIE, J.H.; DICKEY, D.A. Principles and procedures of statistics. A biometrical approach. New York: McGraw-Hill Co., 1997. 666p.

SUÁREZ LODOÑO, A.A.; VALADARES FILHO, S.C.; COELHO DA SILVA, J.F. et al. Somatotropina bovina para vacas em lactação. 2. Consumo, digestibilidade aparente e concentrações ruminais de amônia, pH e taxa de passagem. Revista Brasileira de Zootecnia, v.26, n.6, p.1234-1242, 1997.

TAMMINGA, S. Influence of feeding management on ruminal fiber digestibility. In. JUNG, H.G.; BUXTON, D.R.; HATFIELD, R.D. et al. (Eds.) Forage cell wall structure and digestibility. Madison: American Society of Agronomy, 1993. p.572-602.

TIBO, G.C.; VALADARES FILHO, S.C.; VALADARES, R.F.D. et al. Níveis de concentrado em dietas de novilhos F1 simental $\mathrm{X}$ nelore. 1.Consumo e digestibilidade. Revista Brasileira de Zootecnia, v.29, n.3, p.910-920, 2000.

VALADARES, R.F.; GONÇALVES, L.C.; RODRIGUEZ, N.M. et al. Níveis de proteína bruta em dietas de bovinos. 1.Consumo e digestibilidades aparentes totais e parcias. Revista Brasileira de Zootecnia, v.26, n.6, p.1252-1258, 1997.

Van SOEST, P.J. Nutritional ecology of the ruminant. 2.ed. Ithaca: Cornell University Press, 1994. 476p.

VASQUEZ, O.P.; SMITH, T.R. Factors affecting pasture intake and total dry matter intake in grazing dairy cows.Journal of Dairy Science, v.83, n.10, p.2301-2309, 2000.

VÉRAS, A.S.C.; VALADARES FILHO, S.C.; COELHO DA SILVA, J.F. et al. Consumo e digestibilidade aparente em bovinos nelore não-castrados, alimentados com rações contendo diferentes níveis de concentrado. Revista Brasileira de Zootecnia, v.29, n.6, p.2367-2378, 2000 (Suplemento 2).

VIEIRA, R.A.M.; PEREIRA, J.C.; MALAFAIA, P.A.M. et al. The influence of elephantgrass Pennisetum purpureum Schum. Mineiro variety) growth on the nutrient kinetics in the rumen. Animal Feed Science and Technology, v.67, n.2, p.151-161, 1997.

VIEIRA, R.A.M.; PEREIRA, J.C.; MALAFAIA, P.A.M. et al. Fracionamento dos carboidratos e cinética de degradação in vitro da fibra em detergente neutro da extrusa de bovinos a pasto. Revista Brasileira de Zootecnia, v.29, n.3, p.889897, 2000.

VILELA, S.D.J.; VALADARES FILHO, S.C.; COELHO DA SILVA, J.F. et al. Caroço de algodão para vacas leiteiras. I. Consumo de nutrientes, produção e composição do leite. Revista da Sociedade Brasileira de Zootecnia, v.25, n.2, p.298-308, 1996.

WALDO, D.R. Effect of forage quality on intake and forageconcentrate interactions. Journal of Dairy Science, v.69, n.2, p.617-631, 1986 . 